\title{
Analgesic and Anti-Inflammatory Activities of Sophocarpine from Sophora viciifolia Hance
}

\author{
F. L. Wang, ${ }^{1,2,3}$ H. Wang, ${ }^{1,2,3}$ J. H. Wang, ${ }^{1,2,3}$ D. X. Wang, ${ }^{1,2,3}$ Y. Gao, ${ }^{1,2,3}$ B. Yang, ${ }^{1,2,3}$ \\ H. J. Yang, ${ }^{1}$ Y. B. Ji, ${ }^{1,2,3}$ and G. S. Xin $\mathbb{1}^{1,2,3}$ \\ ${ }^{1}$ School of Pharmacy, Engineering Research Center for Medicine, Harbin University of Commerce, Harbin 150076, China \\ ${ }^{2}$ Engineering Research Center of Natural Anticancer Drugs, Ministry of Education, Harbin 150076, China \\ ${ }^{3}$ Key Laboratory for Drug Research on Prevention and Treatment of Geriatric Diseases of Heilongjiang Province, \\ Harbin 150076, China
}

Correspondence should be addressed to G. S. Xin; 13766801150@163.com

Received 26 September 2020; Revised 12 July 2021; Accepted 7 October 2021; Published 8 November 2021

Academic Editor: Ji-Fu Wei

Copyright (c) 2021 F. L. Wang et al. This is an open access article distributed under the Creative Commons Attribution License, which permits unrestricted use, distribution, and reproduction in any medium, provided the original work is properly cited.

Sophora viciifolia Hance is an edible plant used in traditional Chinese medicine. Sophocarpine, a tetracyclic quinolizidine alkaloid, is one of the most abundant active ingredients in Sophora viciifolia Hance. Here, we study the analgesic and anti-inflammatory effects, as well as the acute toxicity of sophocarpine from Sophora viciifolia Hance in mice. Sophocarpine (20, 40, and $80 \mathrm{mg} / \mathrm{kgbw}$ ) significantly prolonged the delay period before a hot plate reaction occurred (all $P<0.05$ ), and the delay before a tail-flick response was induced by a warm bath $(P<0.05 ; P<0.01)$. Sophocarpine $(40,80 \mathrm{mg} / \mathrm{kg})$ resulted in dose-dependent inhibition of the writhing reaction induced by acetic acid in mice $(P<0.05 ; P<0.001$, respectively). Sophocarpine $(80 \mathrm{mg} / \mathrm{kg})$ reduced the total duration of a formalin-induced pain response $(P<0.05)$. Sophocarpine prolonged the foot-licking latency of mice after the hot plate reaction, and this effect was antagonized by calcium chloride and enhanced by verapamil. Sophocarpine $(20,40$, and $80 \mathrm{mg} / \mathrm{kg})$ significantly inhibited xylene-induced ear edema $(P<0.01 ; P<0.001 ; P<0.001$, respectively) and the penetration of acetic acid-induced dye into the peritoneal cavity $(P<0.01 ; P<0.01 ; P<0.001$, respectively). It also reduced the levels of proinflammatory cytokine interleukin (IL)- $1 \beta$, IL-6, and prostaglandin E2 ( $P<0.05$, $P<0.01, P<0.001)$ and those of serum nitric oxide $(P<0.05)$. The results of this study suggest that sophocarpine possesses certain analgesic and anti-inflammatory activities, which may be related to calcium and inhibition of the secretion of inflammatory factors.

\section{Introduction}

Pain is usually related to inflammation and is the most common manifestation of many diseases [1]. It is associated with the pathophysiology of various clinical conditions, such as arthritis, cancer, and vascular diseases [2]. In inflammatory pain conditions, proinflammatory cytokines (interleukin 1 [IL-1], IL-6, tumor necrosis factor alpha [TNF- $\alpha]$ ) and various small molecules (adenosine triphosphate, bradykinins, prostaglandins) are recruited to the site of injury and act on nociceptors, leading to hyperalgesia, allodynia, and spontaneous pain [3]. High-output nitric oxide (NO) generated by inducible NO synthase can lead to deleterious consequences, such as septic shock and inflammatory diseases [4]. Conven- tional analgesic and anti-inflammatory agents are very often misused. These therapies occasionally fail or produce partial responses. In addition, serious side effects (such as nephrotoxicity, hepatotoxicity, and gastric ulceration) and low efficacy limit the use of these agents [5]. The analgesic and anti-inflammatory effects of natural medicine have become the focus of attention. Sophora viciifolia Hance, which belongs to the butterfly flower family, grows at an altitude of $1,300-2,500 \mathrm{~m}$ and is known as Baicihua in China. It is mainly distributed in the Yunnan, Guizhou, Sichuan, and Ningxia provinces. Conventionally, the flower of Sophora viciifolia Hance is used as a remedy for night sweats, heat stroke, and edema, among other conditions [6]. It is thought that consumption of the flower in springtime may eliminate 
the "toxins" that have accumulated in the human body during the previous season. The active ingredients of Baicihua include sophoramine, sophordine, matrine, oxymatrine, sophocarpine (SC), and oxysophocarpine. At present, there is limited research on the anti-inflammatory and analgesic effects of SC. The purpose of the present study was to investigate the possible analgesic and anti-inflammatory activities of SC in animal models.

\section{Materials and Methods}

2.1. Plant Materials. Flowers of Sophora viciifolia Hance were collected in the Yun-Nan province of China in March 2015 and identified by Professor B. Yang (School of Pharmacy, Harbin University of Commerce, Harbin, China). SC was isolated from Sophora viciifolia Hance [7] with a purity of $>98 \%$, as determined by a Waters HPLC system equipped with a UV detector and C18 column $(250 \times 4.6 \mathrm{~mm} ; 5 \mu \mathrm{m})$. The analyses were performed with a column at $25^{\circ} \mathrm{C}$. The flow rate was maintained at a constant $1.0 \mathrm{~mL} / \mathrm{min}$. A volume:volume ratio of $12: 88$ of acetonitrile: $0.05 \mathrm{~mol} / \mathrm{L} \mathrm{KH}_{2} \mathrm{PO}_{4}$ and $2.0 \mathrm{~mL} / \mathrm{L}$ triethylamine was used as the mobile phase. The detection wavelength was $205 \mathrm{~nm}$. The quantitative determination of SC was performed using an external standard based on the peak area. A reference compound with a purity of $>98 \%$ was obtained from Shanghai Aladdin Biochemical (Shanghai, China).

2.2. Chemicals and Reagents. The following reagents were used in this study: aspirin (Shineway Pharmaceutical; Shijiazhuang, China), normal saline (Sanlian Pharmaceutical; Harbin, China), acetic acid and formalin 37\% (Sinopharm Chemical Reagent Beijing; Beijing, China), verapamil (Central Pharmaceutical; Tianjin, China), xylene (Jingdongtianzheng Precision Chemical Reagent Factory; Tianjin, China), dexamethasone sodium phosphate injection (Zhuofeng Pharmaceutical; Zhengzhou, China), and carrageenan (Sigma-Aldrich; St. Louis, MO, USA). The NO Assay Kit was obtained from Beyotime (Shanghai, China). The prostaglandin E2 (PGE2), IL-1 $\beta$, and IL-6 enzyme-linked immunosorbent assay (ELISA) kits were obtained from Nanjing Jiancheng Bioengineering Institute (Nanjing, China). All other chemicals used in the experiments were of analytical grade.

2.3. Animals. Kunming mice (males, weight: 18-22 g; SCXK(Ji)2016-0003) were provided by Changchun Yisi Experimental Animal Technology. Animals were housed in polycarbonate cages in a temperature- and humiditycontrolled environment with a 12-h light/dark cycle and free access to food and water. All animal experiments complied with the National Institutes of Health (Bethesda, MD, USA) Guide for the Care and Use of Laboratory Animals (NIH Publications No. 8023, revised 1978).

2.4. Acute Toxicity Tests. The animals were fasted overnight prior to the administration of SC. Mice in five groups (six animals per group) were intraperitoneally (i.p.) injected with different doses of SC $(\mathrm{mg} / \mathrm{kg})$. The animals were observed for $1-2 \mathrm{~h}$ after administration for any acute signs of behavioural toxicity. At $48 \mathrm{~h}$ after treatment, the number of deaths was determined. The $\mathrm{LD}_{50}$ of SC (i.e., dose resulting in $50 \%$ mortality) was determined by Probit regression statistical analysis [8].

2.5. Animal Grouping and Dosing. For the analgesic and anti-inflammatory activity test, mice were randomly divided into five groups (i.e., negative control, positive control, and three test groups) comprising 10 animals each (Figure 1). Negative control animals received normal saline $(10 \mathrm{~mL} / \mathrm{kg}$, i.p.), while positive control animals were treated with standard drugs (aspirin, $100 \mathrm{mg} / \mathrm{kg}$, intragastric; dexamethasone, $2.5 \mathrm{mg} / \mathrm{kg}$, i.p.). The remaining three groups received different doses $(20,40$, and $80 \mathrm{mg} / \mathrm{kg}$, i.p.) of SC. Access to food, but not water, was withdrawn $2 \mathrm{~h}$ prior to drug administration.

2.6. Writhing Test. At $30 \mathrm{~min}$ after drug administration, the mice received an i.p. injection of $1 \%$ volume/volume acetic acid solution $(10 \mathrm{~mL} / \mathrm{kg})$. The mice were placed individually in transparent cages. The number of acid-induced writhes was counted for $20 \mathrm{~min}$. For the purpose of scoring, a writhe was indicated by stretching of the abdomen and/or simultaneous stretching of at least one hind limb [9].

2.7. Measurement of NO. After the writhing test, the femoral artery was immediately cut to obtain a blood sample. The total blood sample was centrifuged at $1,097 \times g$ for $10 \mathrm{~min}$ to separate the serum. The levels of NO in the serum were determined using the NO Assay Kit [10].

2.8. Heat Tail-Flick Test. The time required by mice to withdraw (flick) the tail was considered the reaction time [11]. Observations were recorded prior to and at $0.5,1,1.5$, and $2 \mathrm{~h}$ after drug administration.

2.9. Formalin Test. Mice received a subcutaneous injection ( $20 \mu \mathrm{L}$ of $1 \%$ formalin prepared in $0.9 \%$ saline) into the dorsal hind paw and were immediately transferred in a transparent box for observation [12]. The duration of the reaction time (paw licking or biting) was determined from 0-5 min (first phase) and 15-30 min (second phase) after formalin injection.

2.10. Hot Plate Test. Mice were placed in an aluminium hot plate maintained at a temperature of $55 \pm 0.5^{\circ} \mathrm{C}$ [11]. The response latency to a discomfort reaction (licking paws or jumping) was determined before and at 15, 30, 60, 90, and $120 \mathrm{~min}$ after drug administration. The cut-off time was $60 \mathrm{~s}$.

2.11. The Effects of Calcium Chloride $\left(\mathrm{CaCl}_{2}\right)$ and Verapamil on SC Analgesia. A total of 40 mice with a basic pain threshold within 5-30s were randomly divided into four groups: one group treated with normal saline (i.p.) and three groups treated with $80 \mathrm{mg} / \mathrm{kg} \mathrm{SC}$ (i.p.). After $45 \mathrm{~min}$, one group was given $0.3 \mathrm{mg} / \mathrm{kg}$ verapamil intravenously (i.v.), the other group given $5 \mathrm{mg} / \mathrm{kg} \mathrm{CaCl}_{2}$ (i.v.), and the pain threshold was measured again after $15 \mathrm{~min}$ [13]. 


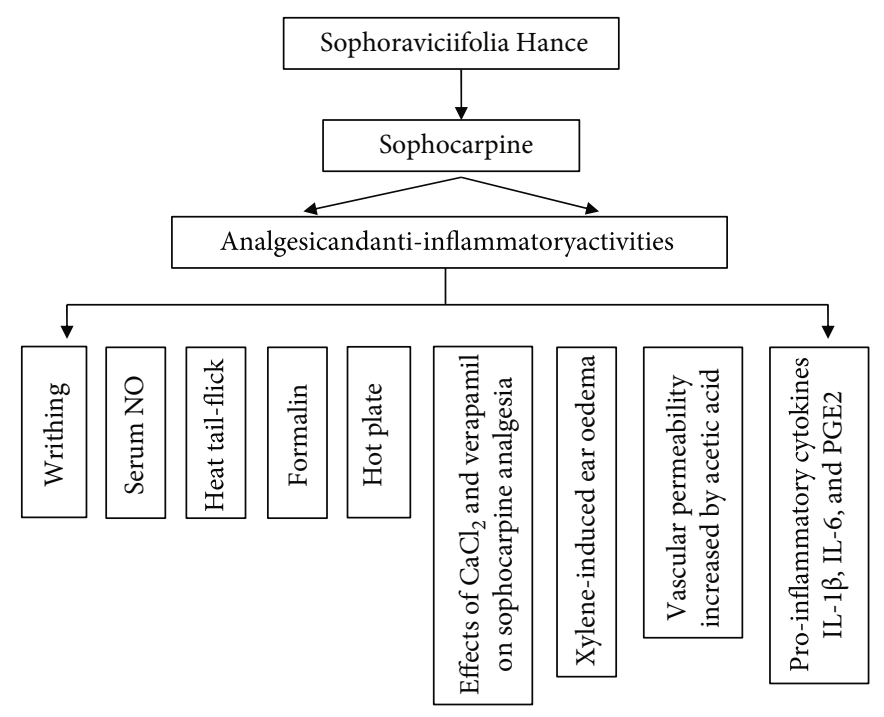

FIgURE 1: Schematic representation of the experiment. Abbreviations: $\mathrm{CaCl}_{2}$ : calcium chloride; IL-1 $\beta$ : interleukin $1 \beta$; interleukin 6: IL-6; NO: nitric oxide; PGE2: prostaglandin E2.

2.12. Xylene-Induced Ear Oedema Test. The mice were treated with normal saline, SC, or dexamethasone for $4 \mathrm{~d}$. On day 4 , at $1 \mathrm{~h}$ after administration, xylene $(30 \mu \mathrm{L})$ was applied to both the anterior and posterior surfaces of the right ear [14]. The left ear was used as control. After $1 \mathrm{~h}$, the mice were sacrificed, and sections (thickness: $9 \mathrm{~mm}$ ) were obtained from both ears using a cork borer. Any increase in weight caused by the irritant was subsequently measured by subtracting the weight of the untreated left ear section from that of the treated right ear section.

2.13. Acetic Acid-Induced Vascular Permeability Test. At $1 \mathrm{~h}$ after administration, mice received an injection of $1 \%$ Evan's blue solution ( $5 \mathrm{~mL} / \mathrm{kg}$, i.v.). After $5 \mathrm{~min}$, each mouse received an injection (i.p.) of $1 \%$ acetic acid solution $(10 \mathrm{~mL} / \mathrm{kg})$. Twenty minutes later, the mice were sacrificed, and the concentration of Evan's blue in the fluid of the peritoneal cavity was determined by measuring the absorbance at $590 \mathrm{~nm}$ [15].

2.14. Analysis of $I L-1 \beta, I L-6$, and PGE2. At $1 \mathrm{~h}$ after drug administration, paw edema was induced by subcutaneously injecting $20 \mu \mathrm{L}$ of freshly prepared $1 \%$ carrageenan solution into the plantar surface of the right hind paw [16]. The mice were sacrificed after $4 \mathrm{~h}$, and the toes of the right hind paw were homogenized and diluted to form a $10 \%$ homogenate. This was centrifuged at $4: \mathrm{C}$ and $9,391 \times g$ for $15 \mathrm{~min}$, and the supernatant was collected. The levels of IL- $1 \beta$, IL- 6 , and PGE2 were determined using ELISA kits according to the instructions provided by the manufacturer [17].

2.15. Statistical Analysis. All experimental data are represented as the mean \pm standard deviation. Analysis of variance was performed using the statistical software SPSS version 18.0 (IBM, Armonk, NY, USA). $P<0.05$ was assumed to indicate a statistically significant difference.
TABLE 1: Effect of SC on acetic acid-induced writhing in mice.

\begin{tabular}{lccc}
\hline Group & Dose $(\mathrm{mg} / \mathrm{kg})$ & Number of writhes & Inhibition $(\%)$ \\
\hline NS & - & $28.38 \pm 7.63$ & - \\
ASP & 100 & $6.08 \pm 3.95^{* * *}$ & 78.59 \\
& 20 & $24.15 \pm 7.34$ & 14.91 \\
SC & 40 & $20.46 \pm 8.70^{*}$ & 27.91 \\
& 80 & $14.85 \pm 6.04^{* * *}$ & 47.70 \\
\hline
\end{tabular}

Abbreviations: ASP: aspirin; NS: normal saline; SD: standard deviation; SC: sophocarpine. Values are expressed as mean $\pm \mathrm{SD}(n=10) .{ }^{*} P<0.05,{ }^{* * *} P$ $<0.001$, compared with the NS control group.

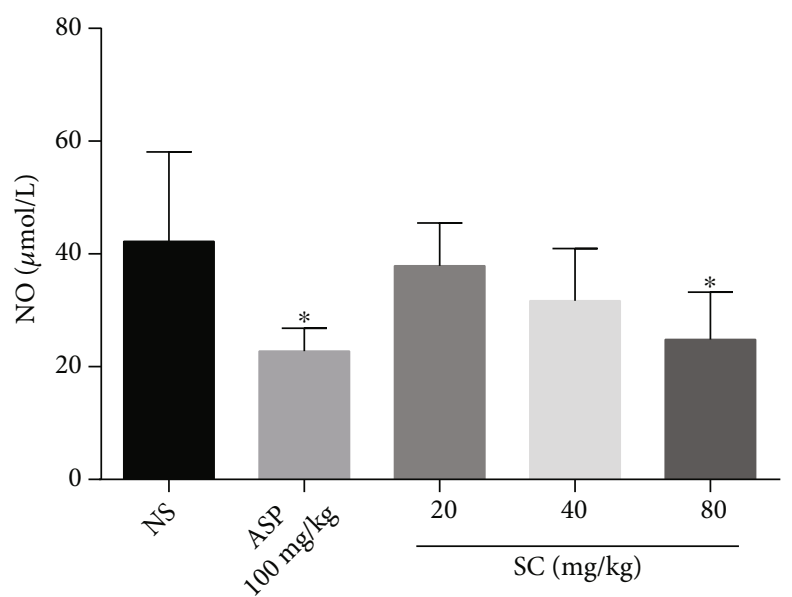

FIgURE 2: Effect of SC on the serum levels of $\mathrm{NO}$ in mice. Abbreviations: ASP: aspirin; SD: standard deviation; NO: nitric oxide; NS: normal saline; SC: sophocarpine. Values are expressed as mean $\pm \mathrm{SD}(n=10) .{ }^{*} P<0.05$, compared with the NS control group. 
TABLE 2: Effect of SC on the tail-flick heat response in mice.

\begin{tabular}{|c|c|c|c|c|c|c|}
\hline \multirow{2}{*}{ Group } & \multirow{2}{*}{ Dose $(\mathrm{mg} / \mathrm{kg})$} & \multicolumn{5}{|c|}{ Response latency (s) } \\
\hline & & $0 \mathrm{~h}$ & $0.5 \mathrm{~h}$ & $1 \mathrm{~h}$ & $1.5 \mathrm{~h}$ & $2 \mathrm{~h}$ \\
\hline NS & - & $3.82 \pm 1.43$ & $3.88 \pm 1.19$ & $3.84 \pm 1.76$ & $3.90 \pm 1.26$ & $3.77 \pm 1.66$ \\
\hline \multirow[t]{2}{*}{ ASP } & 100 & $3.80 \pm 1.11$ & $4.90 \pm 0.86^{*}$ & $4.30 \pm 1.47$ & $5.00 \pm 1.06^{*}$ & $4.75 \pm 1.00$ \\
\hline & 20 & $3.87 \pm 1.10$ & $5.90 \pm 2.51^{*}$ & $5.05 \pm 1.70$ & $5.70 \pm 2.25^{*}$ & $4.95 \pm 1.43$ \\
\hline \multirow[t]{2}{*}{ SC } & 40 & $3.89 \pm 1.12$ & $5.89 \pm 2.28^{*}$ & $5.73 \pm 1.84^{*}$ & $6.03 \pm 1.55^{* *}$ & $5.54 \pm 1.91^{*}$ \\
\hline & 80 & $3.83 \pm 1.47$ & $6.05 \pm 2.08^{*}$ & $6.18 \pm 1.33^{* *}$ & $5.99 \pm 2.20^{*}$ & $5.64 \pm 2.11^{*}$ \\
\hline
\end{tabular}

Abbreviations: ASP: aspirin; NS: normal saline; SD: standard deviation; SC: sophocarpine. Values are expressed as mean \pm SD $(n=10) .{ }^{*} P<0.05,{ }^{* *} P<0.01$, compared with the NS control group.
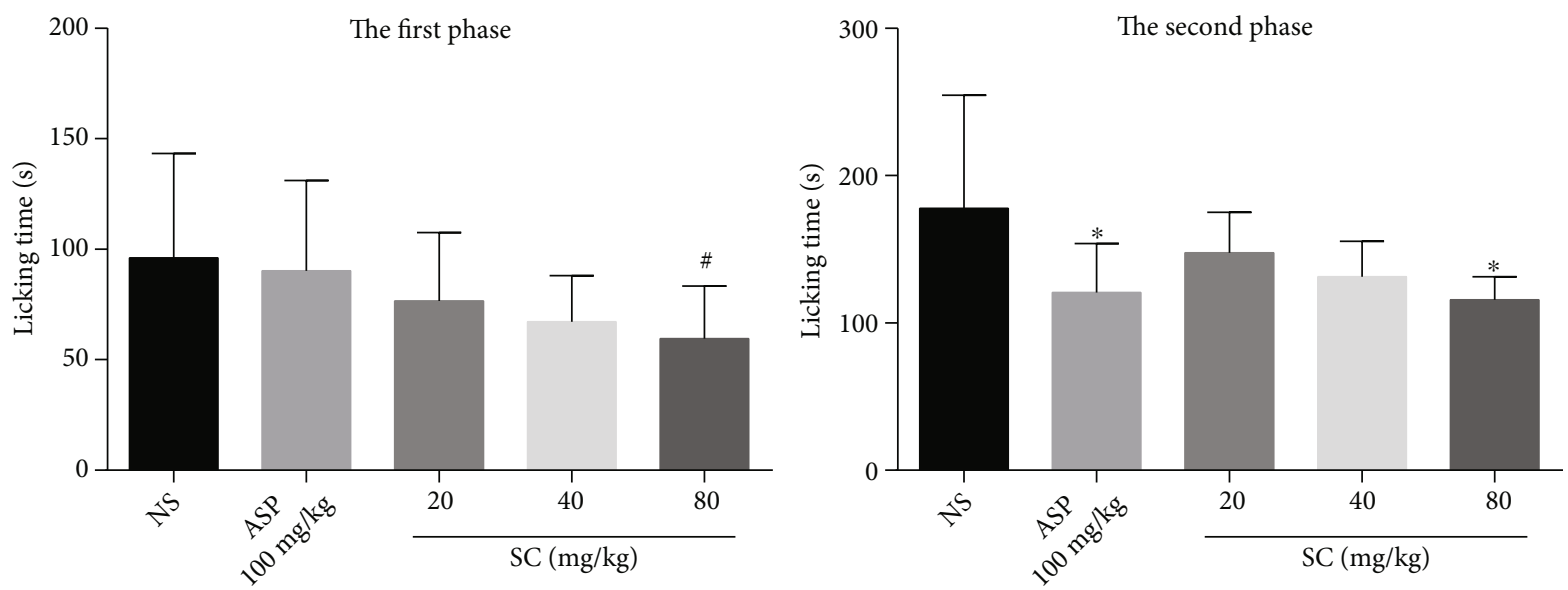

FIGURE 3: Effect of SC in the formalin test. Abbreviations: ASP: aspirin; NS: normal saline; SD: standard deviation; SC: sophocarpine. Values are expressed as mean $\pm \mathrm{SD}(n=10)$. ${ }^{\#} P<0.05$, compared with the NS control group (first phase); ${ }^{*} P<0.05$, compared with the NS control group (second phase).

\section{Results and Conclusions}

3.1. Acute Toxicity Test. The administration of various doses of SC (i.p.) up to $80 \mathrm{mg} / \mathrm{kg}$ did not cause an increase in lethality. The $\mathrm{LD}_{50}$ value of SC was $115 \mathrm{mg} / \mathrm{kg}$, the $\mathrm{LD}_{1}$ value was $85 \mathrm{mg} / \mathrm{kg}$, and a dose not exceeding $\mathrm{LD}_{1}$ was selected as the highest dose.

3.2. Acetic Acid-Induced Writhing Test. The administration of SC $(40,80 \mathrm{mg} / \mathrm{kg})$ caused significant inhibition $(P<0.05$ ; $P<0.001$, respectively) of the nociception induced by acetic acid. At a dose of $80 \mathrm{mg} / \mathrm{kg}$, SC produced a maximum protection of $47.7 \%$. The results were comparable to those obtained for the standard drug aspirin (78.6\% inhibition at $100 \mathrm{mg} / \mathrm{kg}$; Table 1).

3.3. Levels of Serum NO. There was a significant decrease $(P<0.05)$ in NO levels in the group treated with aspirin $(100 \mathrm{mg} / \mathrm{kg})$ compared with the control group. Similarly, treatment with SC $(80 \mathrm{mg} / \mathrm{kg})$ markedly decreased $(P<0.05)$ the levels of NO (Figure 2). The relationship between analgesia and $\mathrm{NO}$ in brain tissue needs further experimental study.

3.4. Heat Tail-Flick Response. Compared with NS, treatment with SC $(20,40$, and $80 \mathrm{mg} / \mathrm{kg})$ significantly prolonged the delay before a tail-flick was generated in response to heat $(P<0.05 ; P<0.01)$. The analgesic effect increased in parallel with the dose, and the efficacy lasted for $2 \mathrm{~h}$ (Table 2 ).

3.5. Formalin Test. Treatment with SC $(80 \mathrm{mg} / \mathrm{kg})$ caused significant $(P<0.05)$ inhibition in the second phase of formalin-induced pain. The paw licking or biting time of mice was $177.9 \pm 76.70 \mathrm{~s}$ in the NS control group and $115.7 \pm 15.72 \mathrm{~s}$ in the $80 \mathrm{mg} / \mathrm{kg}$ SC group. A maximum inhibition of $34.96 \%$ was induced by $80 \mathrm{mg} / \mathrm{kg}$ SC in the second phase of the formalin test. Similarly, treatment with aspirin suppressed the duration of the reaction of the animals in the second phase (Figure 3).

3.6. Hot Plate Test. Treatment with three doses of SC (20, 40, and $80 \mathrm{mg} / \mathrm{kgbw}$ ) significantly increased the latency time in a dose-dependent manner (all $P<0.05$ ). The highest inhibition of response latency was exhibited at the higher dose of $80 \mathrm{mg} / \mathrm{kg}$ SC (17.64-34.37\%), and the maximum effect of SC was observed at $60 \mathrm{~min}$ after drug administration (Table 3).

3.7. Effects of $\mathrm{CaCl}_{2}$ and Verapamil on SC Analgesia. Compared with NS, treatment with SC $(80 \mathrm{mg} / \mathrm{kg})$ effectively prolonged the postlicking foot latency $(P<0.001)$. Compared with the administration of SC alone, $80 \mathrm{mg} / \mathrm{kg} \mathrm{SC}+0.3 \mathrm{mg} / \mathrm{kg}$ 
TABLE 3: Results of the hot plate test for the effect of SC on mice.

\begin{tabular}{|c|c|c|c|c|c|c|c|}
\hline \multirow{2}{*}{ Group } & \multirow{2}{*}{ Dose (mg/kg) } & \multicolumn{6}{|c|}{ Response latency (s) } \\
\hline & & $0 \mathrm{~min}$ & $15 \mathrm{~min}$ & $30 \mathrm{~min}$ & $60 \mathrm{~min}$ & $90 \mathrm{~min}$ & $120 \mathrm{~min}$ \\
\hline NS & - & $19.42 \pm 1.02$ & $18.47 \pm 1.95$ & $18.36 \pm 1.32$ & $20.73 \pm 1.85$ & $20.84 \pm 1.98$ & $19.74 \pm 2.16$ \\
\hline \multirow[t]{2}{*}{ ASP } & 100 & $21.55 \pm 1.75$ & $26.20 \pm 1.55^{* * *}$ & $28.56 \pm 2.35^{* * *}$ & $21.82 \pm 1.49$ & $17.65 \pm 1.44^{* * *}$ & $18.59 \pm 1.76$ \\
\hline & 20 & $20.38 \pm 2.15$ & $21.01 \pm 2.23^{*}$ & $22.04 \pm 3.65^{* *}$ & $23.28 \pm 1.59^{* *}$ & $25.62 \pm 3.20^{* * *}$ & $27.98 \pm 3.13^{* * *}$ \\
\hline \multirow[t]{2}{*}{ SC } & 40 & $22.21 \pm 2.32$ & $23.05 \pm 2.09^{* * *}$ & $24.99 \pm 2.82^{* * *}$ & $26.71 \pm 2.23^{* * *}$ & $23.77 \pm 2.68^{*}$ & $25.04 \pm 1.66^{* * *}$ \\
\hline & 80 & $21.94 \pm 2.42$ & $25.81 \pm 1.17^{* * *}$ & $27.80 \pm 3.12^{* * *}$ & $29.48 \pm 1.96^{* * *}$ & $28.85 \pm 2.40^{* * *}$ & $26.72 \pm 2.44^{* * *}$ \\
\hline
\end{tabular}

Abbreviations: ASP: aspirin; NS: normal saline; SD:standard deviation; SC: sophocarpine. Values are expressed as mean \pm SD $(n=10) .{ }^{*} P<0.05,{ }^{* *} P<0.01$, ${ }^{* * *} P<0.001$, compared with the NS control group.

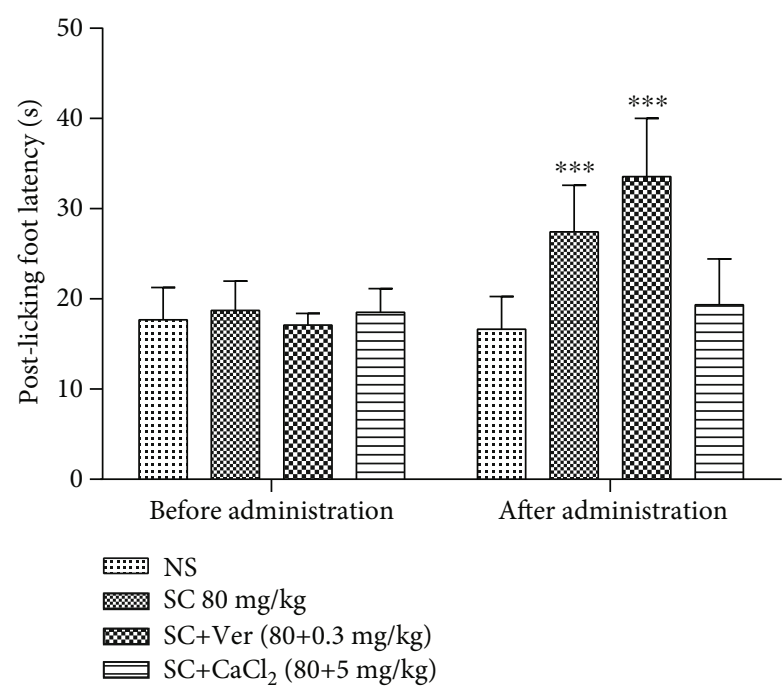

FIGURE 4: Effects of $\mathrm{CaCl}_{2}$ and verapamil on analgesia caused by SC. Abbreviations: $\mathrm{CaCl}_{2}$ : calcium chloride; NS: normal saline; SD: standard deviation; SC: sophocarpine; Ver: verapamil. Values are expressed as mean $\pm \mathrm{SD}(n=10) .{ }^{* *} P<0.001$, compared with the NS control group.

verapamil significantly enhanced the hot plate pain threshold of mice $(P<0.001)$. In contrast, treatment with $80 \mathrm{mg} / \mathrm{kg}$ $\mathrm{SC}+5 \mathrm{mg} / \mathrm{kg} \mathrm{CaCl}_{2}$ reduced the threshold value; this effect was antagonized by $\mathrm{CaCl}_{2}$ (Figure 4 ).

3.8. Xylene-Induced Ear Oedema. Treatment with dexamethasone $(2.5 \mathrm{mg} / \mathrm{kg})$ significantly decreased the xylene-induced mouse ear oedema compared with the NS $(P<0.001)$. In this test, the administration of SC showed a dosedependent edema-inhibiting effect $(P<0.01 ; P<0.001)$. At $20 \mathrm{mg} / \mathrm{kg}$, SC caused an inhibition of $17.9 \%$. The greatest inhibition of edema was exhibited at the higher dose of $80 \mathrm{mg} / \mathrm{kg}$ SC (59.95\%); this value was closer to that obtained for dexamethasone (73.53\%; Table 4).

3.9. Acetic Acid-Induced Vascular Permeability in Mice. Treatment with dexamethasone $(2.5 \mathrm{mg} / \mathrm{kg})$ inhibited acetic acid-induced dye extrusion into the peritoneal cavity by $60.1 \%$. The administration of SC exerted a dose-dependent inhibitory effect on dye extrusion. At $80 \mathrm{mg} / \mathrm{kg}$, the inhibition rate induced by SC was $45.4 \%$ (Table 5).
TABLE 4: Effect of SC on xylene-induced ear swelling in mice.

\begin{tabular}{lccc}
\hline Group & Dose $(\mathrm{mg} / \mathrm{kg})$ & Swelling & Inhibition $(\%)$ \\
\hline NS & - & $33.53 \pm 4.74$ & - \\
DEX & 2.5 & $8.88 \pm 3.24^{* * *}$ & 73.53 \\
& 20 & $27.53 \pm 3.99^{* *}$ & 17.90 \\
SC & 40 & $22.46 \pm 2.82^{* * *}$ & 33.02 \\
& 80 & $13.43 \pm 4.51^{* * *}$ & 59.95 \\
\hline
\end{tabular}

Abbreviations: NS: normal saline; SD: standard deviation; DEX: dexamethasone; SC: sophocarpine. Values are expressed as mean \pm SD $(n=10) .{ }^{* *} P<0.01,{ }^{* * *} P<0.001$, compared with the NS control group.

TABLE 5: Effect of SC on acetic acid-induced vascular permeability in mice.

\begin{tabular}{lccc}
\hline Group & Dose $(\mathrm{mg} / \mathrm{kg})$ & OD & Inhibition $(\%)$ \\
\hline NS & - & $0.87 \pm 0.21$ & - \\
DEX & 2.5 & $0.35 \pm 0.12^{* * *}$ & 60.09 \\
& 20 & $0.59 \pm 0.19^{* *}$ & 31.70 \\
SC & 40 & $0.56 \pm 0.16^{* *}$ & 36.13 \\
& 80 & $0.48 \pm 0.17^{* * *}$ & 45.36 \\
\hline
\end{tabular}

Abbreviations: DEX: dexamethasone; NS: normal saline; OD: optical density; SD: standard deviation; SC: sophocarpine. Values are expressed as mean \pm SD $(n=10) .{ }^{* *} P<0.01,{ }^{* * *} P<0.001$, compared with the NS control group.

3.10. Expression of $I L-1 \beta, I L-6$, and PGE2. Compared with NS, treatment with SC (40 or $80 \mathrm{mg} / \mathrm{kg}$ ) significantly decreased the expression levels of proinflammatory factors IL-1 $\beta$, IL-6, and PGE2 in the damaged tissues of mice $(P<0.01 ; P<0.001$; Figure 5).

\section{Discussion}

Male mice were used in all analgesic and anti-inflammatory models because pain sensitivity changes across the menstrual cycle [18], and estrogen exerts anti-inflammatory activity [19]. Hence, female mice were excluded from this analysis to avoid any fluctuation in the results. The heat tail-flick test was used to investigate the central analgesic activity [20], and the degree of pain was determined by observing the time when mice shook their tails away from the stimulus source due to thermal stimulation. The acetic acid-induced writhing test 


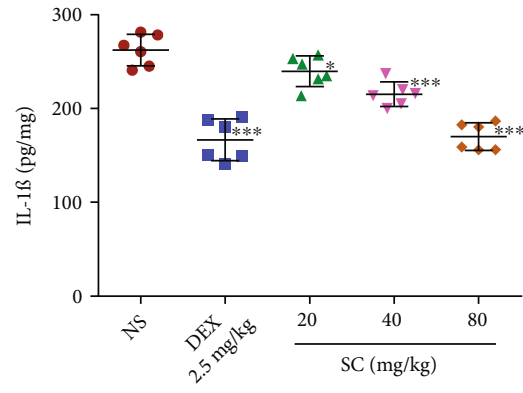

(a)

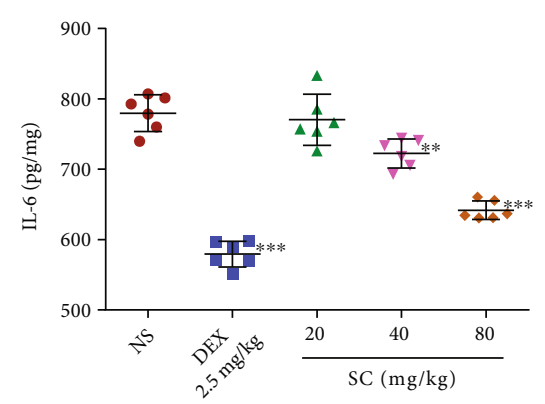

(b)

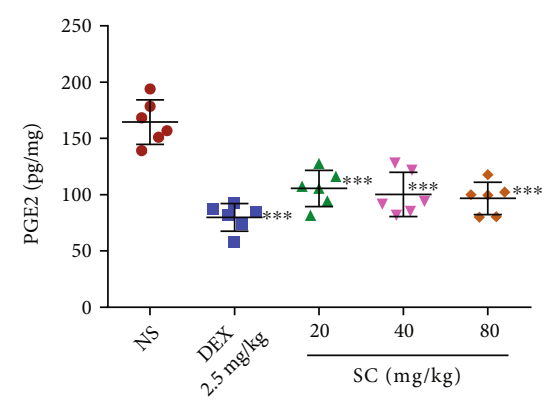

(c)

FIGURE 5: Effects of SC on the carrageenan-induced expression of IL-1 $\beta$ (a), IL-6 (b), and PGE2 (c) in mice with inflammatory pain. Abbreviations: DEX: dexamethasone; IL-1 $\beta$ : interleukin 1 $\beta$; IL-6: interleukin 6; NS: normal saline; PGE2: prostaglandin E2; SD: standard deviation; SC: sophocarpine. Values are expressed as mean $\pm \mathrm{SD}(n=6) .{ }^{*} P<0.05,{ }^{* *} P<0.01,{ }^{* * *} P<0.001$, compared with the NS control group.

[21] was utilized to observe the peripheral analgesic effects. Of note, the acetic acid-induced writing test is effective but nonselective [22]. Therefore, the analgesic effect of SC was further investigated using the formalin test. Subcutaneous injection of formalin induced two distinct pain responses. The first phase is acute pain caused by direct stimulation of peripheral pain-sensitive neurons by formalin, while the second phase is chronic pain caused by activation of ventral horn neurons at the spinal cord level. The hot plate test is a well-validated model that animals were only subjected to thermal stimulation once, resulting in very slight tissue damage, and the experimental results were repeatable and reliable for the detection of the analgesic effects of several types of drugs [23]. Xyleneinduced ear swelling model in mice is widely used in the evaluation of anti-inflammatory drug efficacy and antiinflammatory activity screening of compounds. Xylene is a commonly used inflammatory agent, which can induce the release of histamine, kinin, and fibrinolytic enzyme and then cause the increase of local capillary permeability, inflammatory cell infiltration, and acute exudative inflammatory edema. The results showed that SC showed effective analgesic activity in formalin test, hot plate test, and heat tail-flick test. SC exerted a good analgesic effect. SC inhibited the infiltration of local inflammatory cells and the release of inflammatory mediators, thus produced a significant inhibitory effect on xylene-induced ear swelling inflammation in mice, caused capillary contraction, and reduced acetic acid-induced vascular permeability, which proved that SC had a good antiinflammatory effect on acute inflammation. TNF- $\alpha$ is a major cytokines, involved in acute and chronic inflammation, inducing other cytokines, including IL- $1 \beta$ and IL- 6 , activating the neutrophils and upregulation adhesion molecules. TNF- $\alpha$ can also promote the synthesis of PGE2, leading to blood flow changes and the resulting edema. In order to determine the mechanism of action of SC as an anti-inflammatory agent, the levels of IL-1 $\beta$, IL-6, and PGE2 in the supernatant of mouse toe homogenate were analyzed. The results indicated that SC significantly reduced the expression of IL- $1 \beta$, IL-6, and PGE2 [24] in the inflammation model. Hence, the antiinflammatory effect of SC may be related to cytokine levels.

Calcium $\left(\mathrm{Ca}^{2+}\right)$ is involved in pain regulation. Blocking the internal flow of calcium ions can affect the sensory conduction process and produce an anti-injury response [25]. $\mathrm{NO}$ is a small inorganic molecule that plays an important role in signal transmission in the central and peripheral nervous system. It increases the levels of guanosine cyclophosphate in neurons, which is the basis of central sensitization mediated by protein kinase G. Activation of protein kinase $\mathrm{G}$ and cyclic guanosine phosphate can increase the intracellular $\mathrm{Ca}^{2+}$ concentration by modifying voltage-gated $\mathrm{Ca}^{2+}$ channels and mobilizing intracellular $\mathrm{Ca}^{2+}$ reservoir release. The increased intracellular $\mathrm{Ca}^{2+}$ concentration in turn activates calmodulin, which activates NO synthase to synthesize NO. As a second messenger, NO reversibly diffuses across the cell membrane to the presynaptic primary afferent terminal. This process further enhances the release of excitatory amino acids and neuropeptides and participates in the signal transmission of harmful reactions [26]. The analgesic effect of SC was antagonized by $\mathrm{CaCl}_{2}$ and enhanced by verapamil. These findings suggest that SC may affect $\mathrm{Ca}^{2+}$ influx, thereby reducing the production of $\mathrm{NO}$ and subsequently exerting analgesic effects. 


\section{Data Availability}

The data used to support the findings of this study are included in the article.

\section{Conflicts of Interest}

The authors declare that they have no conflicts of interest.

\section{Acknowledgments}

This work was supported by the Youth Innovative Talent Support Program of Harbin University of Commerce (grant no. 2020CX31), the Heilongjiang Province Natural Science Foundation Joint Guidance Project (grant no. LH2019H066), and the China Postdoctoral Foundation Project (grant no. 2016M601440).

\section{References}

[1] K.-D. Tripathi, Essential of medical pharmacology, Jaypee Brothers Medical Publishers, 6th ed edition, 2010.

[2] R.-R. Ji, A. Chamessian, and Y.-Q. Zhang, "Pain regulation by non-neuronal cells and inflammation," Science, vol. 354, no. 6312 , pp. 572-577, 2016.

[3] S. Khan, O. Shehzad, J. Chun et al., "Anti-hyperalgesic and anti-allodynic activities of capillarisin via suppression of inflammatory signaling in animal model," Journal of Ethnopharmacology, vol. 152, no. 3, pp. 478-486, 2014.

[4] T. Okuyama, R. Nakatake, M. Kaibori, T. Okumura, M. Kon, and M. Nishizawa, "A sense oligonucleotide to inducible nitric oxide synthase mRNA increases the survival rate of rats in septic shock," Nitric Oxide: Biology and Chemistry, vol. 72, pp. 3240, 2018.

[5] A. Gibofsky, "Current therapeutic agents and treatment paradigms for the management of rheumatoid arthritis," American Journal of Managed Care, vol. 20, no. 7, pp. S136-S144, 2014.

[6] Z.-G. Tai, L. Cai, L. Dai et al., "Antioxidant activity and chemical constituents of edible flower of Sophora viciifolia," Food Chemistry, vol. 126, no. 4, pp. 1648-1654, 2011.

[7] Y. Zhang, F. Pan, B. He, and Y. Wang, "HPLC fingerprint and contents of three kinds of alkaloids of Sophora davidii (Franch.) Skeels," Natural Product Research and Development, vol. 31, no. 5, pp. 797-802, 2019.

[8] S.-Y. Xu, Methodology of pharmacological experiment, People's Health Publishers, Beijing, 1991.

[9] Y. Tamrat, T. Nedi, S. Assefa, T. Teklehaymanot, and W. Shibeshi, "Anti-inflammatory and analgesic activities of solvent fractions of the leaves of Moringa stenopetala Bak. (Moringaceae) in mice models," BMC Complementary and Alternative Medicine, vol. 17, no. 1, p. 473, 2017.

[10] A.-A.-O. Abeed, G.-A.-A. Jaleel, and M.-S.-K. Youssef, "Novel heterocyclic hybrids based on 2-pyrazoline: synthesis and assessment of anti-inflammatory and analgesic activities," Current Organic Synthesis, vol. 16, no. 6, pp. 921-930, 2019.

[11] D. Masroor, S.-G. Baig, S. Ahmed, S. M. Ahmad, and M. M. Hasan, "Analgesic, anti-inflammatory and diuretic activities of Cicer arietinum L," Pakistan Journal of Pharmaceutical Sciences, vol. 31, no. 2, pp. 553-558, 2018.

[12] A. Ahmadi, M. Khalili, Z. Olama, S. Karami, and B. NahriNiknafs, "Synthesis and study of analgesic and anti- inflammatory activities of amide derivatives of ibuprofen," Mini Reviews in Medicinal Chemistry, vol. 17, no. 9, pp. 799804, 2017.

[13] J. Chen and L. Yang, "Study on analgesic and antiinflammatory effects and mechanism of sophoramine," Chinese Archives of Traditional Chinese Medicine, vol. 35, no. 6, pp. 1424-1427, 2017.

[14] A. Iqbal, S.-U. Din, J. Bakht, I. U. Khan, and Z. Shah, “Antiinflammatory, anti-pyretic and analgesic activities of Tamarix dioica," Pakistan Journal of Pharmaceutical Sciences, vol. 32, no. 5, pp. 2083-2089, 2019.

[15] L.-L. Gong, S. Yang, H. Liu et al., "Anti-nociceptive and antiinflammatory potentials of Akebia saponin D," European Journal of Pharmacology, vol. 845, pp. 85-90, 2019.

[16] E.-M. Rock, C.-L. Limebeer, and L.-A. Parker, "Effect of cannabidiolic acid and $\Delta 9$-tetrahydrocannabinol on carrageenaninduced hyperalgesia and edema in a rodent model of inflammatory pain," Psychopharmacology, vol. 235, no. 11, pp. 3259$3271,2018$.

[17] H.-H. Yu, Y. Lin, R. Zeng et al., "Analgesic and antiinflammatory effects and molecular mechanisms of _Kadsura heteroclita_stems, an anti-arthritic Chinese Tujia ethnomedicinal herb," Journal of Ethnopharmacology, vol. 238, p. 111902, 2019.

[18] E.-J. Bartley and R.-B. Fillingim, "Sex differences in pain: a brief review of clinical and experimental findings," British Journal of Anaesthesia, vol. 111, no. 1, pp. 52-58, 2013.

[19] B. Sun, D. Yang, Y.-Z. Yin, and J. Xiao, "Estrogenic and antiinflammatory effects of pseudoprotodioscin in atherosclerosis-prone mice: insights into endothelial cells and perivascular adipose tissues," European Journal of Pharmacology, vol. 869, p. 172887, 2020.

[20] B. Kaygisiz, F.-S. Kilic, N. Senguleroglu, C. Baydemir, and K. Erol, "The antinociceptive effect and mechanisms of action of pregabalin in mice," Pharmacological Reports, vol. 67, no. 1, pp. 129-133, 2015.

[21] S.-D.-G. Pacheco, A.-T. Gasparin, C.-H.-A. Jesus et al., "Antinociceptive and anti-inflammatory effects of Bixin, a carotenoid extracted from the seeds of Bixa orellana," Planta Medica, vol. 85, no. 16, pp. 1216-1224, 2019.

[22] G.-H. Vogel and W.-H. Vogel, "Analgesic, anti-inflammatory, and anti-pyretic activity," in Drug discovery and Evaluation, Pharmacological assays, pp. 360-418, Springer-Verlag, Berlin Heidelberg, Germany, 1997.

[23] S.-R. Karna, K. Kongara, P.-M. Singh, P. Chambers, and N. Lopez-Villalobos, "Evaluation of analgesic interaction between morphine, dexmedetomidine and maropitant using hot-plate and tail-flick tests in rats," Veterinary Anaesthesia and Analgesia, vol. 46, no. 4, pp. 476-482, 2019.

[24] N. Liu, G.-X. Zhang, Y.-T. Niu et al., "Anti-inflammatory and analgesic activities of indigo through regulating the IKK$\beta / \mathrm{I} \kappa \mathrm{B} / \mathrm{NF}-\kappa \mathrm{B}$ pathway in mice," Food \& Function, vol. 11, no. 10, pp. 8537-8546, 2020.

[25] M. Nazıroğlu, A. Öz, and K. Yıldızhan, "Selenium and neurological diseases: focus on peripheral pain and TRP channels," Current Neuropharmacology, vol. 18, no. 6, pp. 501-517, 2020.

[26] E.-M. Zanchet, I. Longo, and Y. Cury, "Involvement of spinal neurokinins, excitatory amino acids, proinflammatory cytokines, nitric oxide and prostanoids in pain facilitation induced by Phoneutria nigriventer spider venom," Brain Research, vol. 1021, no. 1, pp. 101-111, 2004. 